\title{
CROSYMED Project: Enhancing Nutrient Use Efficiency through Legumes in Agroecosystems of the Mediterranean Basin
}

\author{
Mohamed Lazali ${ }^{1, *}$, Simon Boudsocq ${ }^{2}$, Elisa Taschen ${ }^{2}$, Mohamed Farissi ${ }^{3}$, Wissem Hamdi ${ }^{4}$, Parthenopi Ralli ${ }^{5}(\mathbb{C}$ \\ and Hervé Sentenac ${ }^{6}$
}

1 Laboratoire de Recherche ERP, Faculté des Sciences de la Nature et de la Vie et des Sciences de la Terre, Université de Khemis Miliana, Khemis Miliana 44225, Algeria

2 UMR Ecologie Fonctionnelle \& Biogéochimie des Sols et Agroécosystèmes, INRAE-IRD-CIRAD-SupAgro, University Montpellier, 34060 Montpellier, France; simon.boudsocq@inrae.fr (S.B.); elisa.taschen@inrae.fr (E.T.)

3 Laboratory of Biotechnology \& Sustainable Development of Natural Resources, Polydisciplinary Faculty, Sultan Moulay Slimane University, Béni Mellal 23000, Morocco; mohamed.farissi@usms.ac.ma

4 Higher Institute of the Sciences and Techniques of Waters of Gabès, Gabès University, Gabès 6072, Tunisia; wissemhemdi@yahoo.fr

5 Hellenic Agricultural Organization-Demeter, Institute of Plant Breeding and Genetic Resources, Thermi, 57001 Thessaloniki, Greece; pralli@ipgrb.gr

6 Biochimie et Physiologie Moléculaire des Plantes, UMR BPMP, CNRS, INRAE, Montpellier SupAgro, University Montpellier, 34060 Montpellier, France; herve.sentenac@inrae.fr

* Correspondence: m.lazali@univ-dbkm.dz; Tel.: +213-6-64-55-73-45

check for updates

Citation: Lazali, M.; Boudsocq, S.; Taschen, E.; Farissi, M.; Hamdi, W.; Ralli, P.; Sentenac, H. CROSYMED Project: Enhancing Nutrient Use Efficiency through Legumes in Agroecosystems of the Mediterranean Basin. Sustainability 2021, 13, 4695. https://doi.org/10.3390/su13094695

Academic Editors: Lucia Rocchi and Luisa Paolotti

Received: 5 January 2021

Accepted: 16 February 2021

Published: 22 April 2021

Publisher's Note: MDPI stays neutral with regard to jurisdictional claims in published maps and institutional affiliations.

Copyright: (c) 2021 by the authors. Licensee MDPI, Basel, Switzerland. This article is an open access article distributed under the terms and conditions of the Creative Commons Attribution (CC BY) license (https:/ / creativecommons.org/licenses/by/ $4.0 /)$.
Abstract: Modern intensive agricultural systems generally focus on the productivity of monocultures. They are characterized by a low diversity of crops, with uniform and symmetrical planting layouts. They largely rely on the utilization of chemical inputs. They are widely denounced for their negative environmental impacts. In this context, the ecological intensification framework proposes the exploitation of biodiversity in order to better achieve such ecosystem services and soil conservation. Intercropping, i.e., the simultaneous growth of two or more crops mixed in the same field, appears to have the potentialities to improve the productivity, resilience capacity, and ecological sustainability of agroecosystems through the intensification of such positive interactions between plants as facilitation and niche complementarity. Cereal-legume intercropping turns out to be effective in low- $\mathrm{N}$ agroecosystems, since legumes have the ability to fix atmospheric nitrogen via their symbiosis with rhizobia. This fixed $\mathrm{N}$, in turn, benefits the cereal through various ecological processes. The objective of the project is to improve the benefit of legumes for intercropped cereals in low-input agroecosystems through the management of plant-plant and plant-microbe interactions. The nitrogen-fixing symbiosis requires phosphorus and iron to be efficient. While these nutrients are prone to be lacking in N-limited agroecosystems, as is the case in Mediterranean agroecosystems, plant-plant interactions and rhizobacteria and mycorrhiza interactions seem to play an important role in their acquisition and efficient utilization. We propose the development of a participatory research project in four Mediterranean agroecosystems. Agronomic and environmental diagnosis will be performed in the field to assess $\mathrm{N}$ and P biogeochemical cycles, as well as Fe availability, in combination with the plant performances and the diversity of soil microorganisms. Molecular identification of soil microorganisms from the most productive sites will be done and research of genes for tolerance to Fe- and P-deficiencies will be realized. Glasshouse experiments involving various cultivars of cereals and legumes, as well as the previously identified microorganisms, will be done in order to disentangle the various mechanisms of nutrient acquisition, sharing, and transfer between plants. Other experiments will assess the effects of cereal-legume-microbe interactions on the development and architecture of the plant root systems and root hair development. The lines of research are integrated with a strategy of functional ecology on plant-microbe-soil interactions in the agroecosystems of Gabès (Tunisia), Boumedfaa (Algeria), Beni Mellal (Morocco), and Thessaloniki (Greece). Using multidisciplinary and innovative approaches, the program will provide novel knowledge and understanding of agroecosystem management for food production. 
Keywords: agroecosystems; agroecology; biodiversity; legumes; abiotic stresses; sustainable agriculture; Mediterranean basin

\section{Introduction}

In the coming decades, agriculture will face major challenges, as it has to increase crop productivity per land unit to feed the global growing population while reducing its footprint on the environment. Global climatic changes, scarcity of arable lands, and limited nonrenewable resources alongside multiple environmental pressures will add another level of complexity to sustain agroecosystems. To achieve global food security under these pressures and ensure sustainable development, agriculture should require both healthy and productive agroecosystems wherein aboveground and belowground interactions in staple crops are optimized to eco-intensify crop production. As pointed out by Vance et al. [1], by 2030, the world population will increase by about +33 to $+67 \%$, while in the meantime, the potential increase in surface area of arable land will reach at most $+20 \%$, and that of irrigated land will be less than $+10 \%$. Given the ongoing climate changes and the increasing use of arable land for other uses than food production, the challenge in front of us is even greater [2]: the level of crop productivity needs to be maintained, but this has to be achieved in a sustainable manner, both environmentally and economically, in order to preserve ecosystem services. The Millennium Ecosystem Assessment underlined that the cycles of nutrients, especially nitrogen $(\mathrm{N})$ and phosphorus $(\mathrm{P})$, were among the most affected ecosystem services, leading to a massive and fast-increasing eutrophication of aquatic ecosystems [3] and contamination of groundwater by nitrate. These phenomena are the direct consequence of the considerable increase in agricultural inputs and the steady decrease of their efficiency [2]: from 1965 to 2000, the doubling of the production of world agriculture corresponded with a 3.5- and 6.9-fold increase in the amounts of $\mathrm{P}$ and $\mathrm{N}$ fertilizers applied, respectively [4]. Besides the effects of eutrophication and of nitrate in drinking water, the high and fast-increasing cost of energy-and thus the increasing cost of manufactured $\mathrm{N}$ fertilizers, as well as the increasing negative impacts of greenhouse gas emissions-invalidates the perspective of pursuing the steady increase in $\mathrm{N}$ fertilizer application. In other words, soil $\mathrm{N}$ and $\mathrm{P}$ resource use efficiency must be increased in agroecosystems. We postulate that one way to improve these efficiencies can be the establishment of greater functional diversity in plant communities of cereals or other grain crops [5].

The challenge of ecological intensification of agroecosystems to achieve crop productivity at lower input levels requires new paradigms to be defined in order to reconcile the production of biomass for diverse uses and other ecosystem services. Intercropping practices are a valuable way of ecological intensification in order to ensure food security and sustainable development. Intercropping cereals with legumes can sustain higher yields [5,6]; enhance resource use efficiency; improve soil conservation and yield stability; and control weeds, insects, or diseases compared with monoculture [7]. Intercropping, as an eco-friendly and cleaner production system, is defined as the growing of two or more species simultaneously on the same area of land. The crops are not necessarily sown and harvested at the same time, but the crops must co-occur for a significant period of their growth $[8,9]$. Intercropping is an old and widespread practice in low-input farming systems of the tropics. Plant species grown in intercropping systems are rather diverse, and most often combine a cereal such as wheat, barley, or maize and a legume such pea, white lupin, chickpea, peanut, or faba bean. Connoly et al. [10] found that $80 \%$ of published intercrop research was conducted in Africa and Asia. Li et al. [11] reported that intercropped plants could yield up to $20-50 \%$ more than when grown separately. Intercropping is not very widespread in temperate agroecosystems but cereal legume intercrops are gaining increasing interest in low-input farming systems, especially in organic farming in Europe. Indeed, this practice is known to increase grain $\mathrm{N}$ concentration of cereal and therefore 
can contribute to the development of agroecosystems that combine high productivity and ecological services [12,13].

The mechanisms underlying the overall yield increase of intercropping compared with monocropping systems have been explained by two major ecological principles leading to improved resource use: niche complementarity and interspecific facilitation [14]. The yield advantage of cereal-legume intercrops is often explained by the complementary use of $\mathrm{N}$ sources by the different components. Legumes and nonlegumes may complement each other in the use of $\mathrm{N}$ sources since although both use soil inorganic $\mathrm{N}$ sources, the legume can also fix atmospheric $\mathrm{N}_{2}$ by rhizobial symbiosis. This complementary use of soil and atmospheric $\mathrm{N}$ sources is of particular interest in cropping systems where inorganic $\mathrm{N}$ is a limited resource [15]. In recent years, several studies have shown that diverse rhizosphere processes might contribute to increasing the performances of the associated species, either both or at least one of the two components, by facilitating access to some nutrient resources that would otherwise not be available $[16,17]$. According to Hauggard-Nielsen and Jensen [14], root facilitation is regarded as a fundamental process in the dynamics of plant communities and is important to include among other agronomic factors affecting the efficiencies of various intercropping systems. These facilitative root interactions within intercropped species integrate a wide range of ecological services, each influenced by local climate and growth conditions as well as choice of species. In addition, the implication of $\mathrm{P}$ nutrition in facilitation among intercropped cereal-legume species is quite documented, although the underlying rhizosphere processes have not been fully elucidated $[18,19]$. Several works have suggested that the legume could facilitate the acquisition of $\mathrm{P}$ by the intercropped cereal via (i) exudation of organic acids $[20,21]$, (ii) protons due to $\mathrm{N}_{2}$ fixation [22,23], and (iii) phosphatase enzymes [24-26]. To further understand those rhizosphere facilitation processes, besides root functional traits of each of the intercropped species, differences of functional diversity of their microbial communities might be worth investigating, especially for those relevant to $\mathrm{N}$ and $\mathrm{P}$ cycles [27-29].

\section{Scientific Quality of the Project}

\subsection{Relevance of the Proposal}

The objective of ecological intensification of agroecosystems, which is challenged by global changes [30], requires searching for more efficient agricultural practices leading to increased and/or more stable performances. Evidence showing that intercropping practices can contribute to this objective has been obtained [29]. However, the beneficial outputs of intercropping can be strongly modulated by pedoclimatic conditions of the agroecosystem [5]. The program we propose takes into account specificities of the Mediterranean area: the semi-arid climate; the importance of cereals and especially of durum wheat (Triticum turgidum L. subsp. durum); and the large diversity of soil and climate conditions, which requires the use of locally adapted plant cultivars and associated symbiotic microorganisms. Clearly, characterizing Mediterranean agroecosystems in which cereal-legume intercropping can lead to significant economic and environmental outputs and understanding the mechanisms underlying such benefits are highly relevant to ARIMNet2 objectives.

Finally, by focusing our proposal on durum wheat and chickpea, we will address highly important socioeconomic development issues. It should be noted, for instance, that the Mediterranean area consumes about $60 \%$ of the world's durum wheat production and is the region that imports the largest amount of this cereal in the world. Being one of the major pulse crops in the world, chickpea (Cicer arietinum L.) is traditionally cultivated in many countries of different continents. It ranks third globally in total yield among grain legume crops. Chickpea has a high nutritive value and serves as an important source of protein in developing countries; it also has the ability to increase soil fertility in terms of soil nitrogen $(\mathrm{N})$ content because of the activity of symbiotic nitrogen fixation. 


\subsection{Aim, Objectives, and Hypotheses}

The general objective of CROSYMED is to increase the mutual benefit of legume-cereal intercropping in Mediterranean agroecosystems and to promote their implantation. More precisely, we aim to understand the positive effects of each intercrop on the other one through four different approaches: (i) field evaluation of the environmental conditions and combinations of varieties/cultivars leading to the highest benefits of intercropping; (ii) identification of the microbial symbiotic and rhizospheric communities associated with the best intercropping performances; and (iii) analysis of the processes responsible for the positive effects of intercropping, implying N, P, and Fe acquisition and sharing. Finally, we aim at transferring the knowledge gained by this project from the scientific community to the farmers (Figure 1).

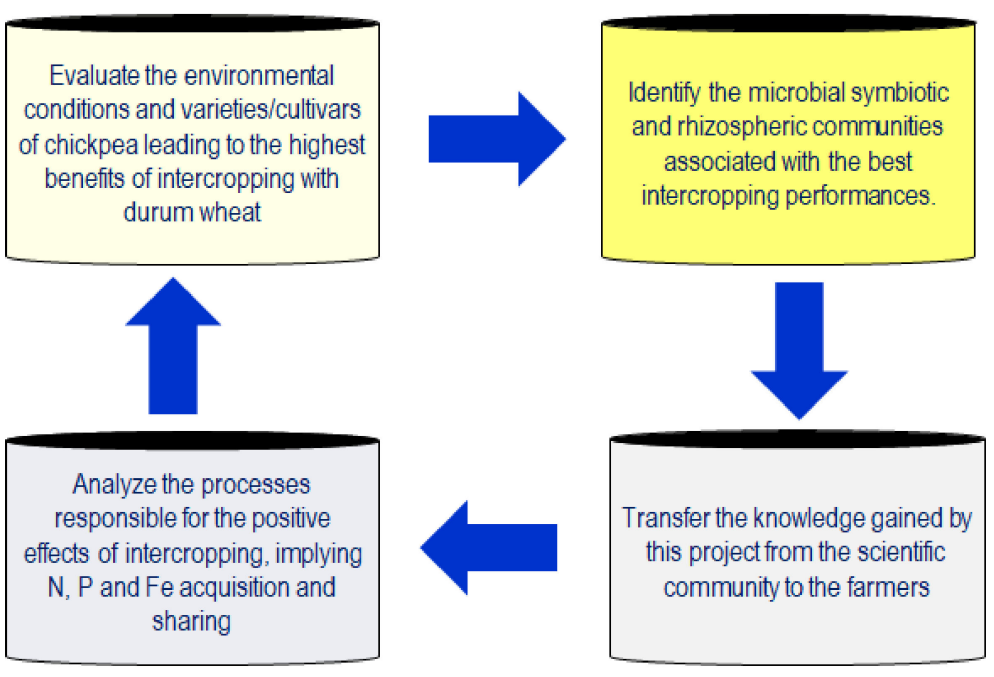

Figure 1. Objectives of the CROSYMED project.

Major hypotheses that will be checked by the program can be summarized as follows:

(1) Intercropping benefits, as previously evidenced [5], are expected to be very efficient in our reference agroecosystems since they are characterized by low availabilities of mineral N, P, and Fe, which is partly due to the calcareous nature of Mediterranean soils.

(2) Legumes have the ability to enhance $\mathrm{P}$ availability through rhizosphere acidification, exudation of organic acids, and excretion of enzymes (e.g., phytases). They can also provide access to more $\mathrm{P}$ through mycorrhizal symbiosis [31]. We hypothesize that, in intercropping conditions, these mechanisms not only benefit the legume and result in more efficient symbiotic nitrogen fixation, but also benefit the P nutrition of the cereal through facilitation.

(3) We also hypothesize that the well-known improved $\mathrm{N}$ nutrition of cereals intercropped with legumes (by niche complementarity and eventually by $\mathrm{N}$ transfer through mycorrhizal networks [23]) will be enhanced by the above-cited mechanisms of $P$ acquisition and transfer.

(4) Cereal can adapt to Fe deficiency through exudation of siderophores, which increase Fe availability for the plant [18]. We hypothesize that legumes intercropped with cereals will benefit from the presence of these siderophores.

(5) Available evidence indicates that rhizobia can behave as bona fide plant-growthpromoting bacteria (PGPB) upon interaction with nonlegume species [32] including durum wheat (unpublished data from our consortium). Since legumes increase the abundance of rhizobia, we hypothesize that the intermingling of legume roots with cereal roots will promote the elongation of the cereal root hairs and thereby increase the root system capacity to take up nutrients. 
3. Quality and Effectiveness of the Scientific Project and Associated Work Plan

3.1. Methodology

The whole project has been organized into six work packages (WPs) (Figure 2).

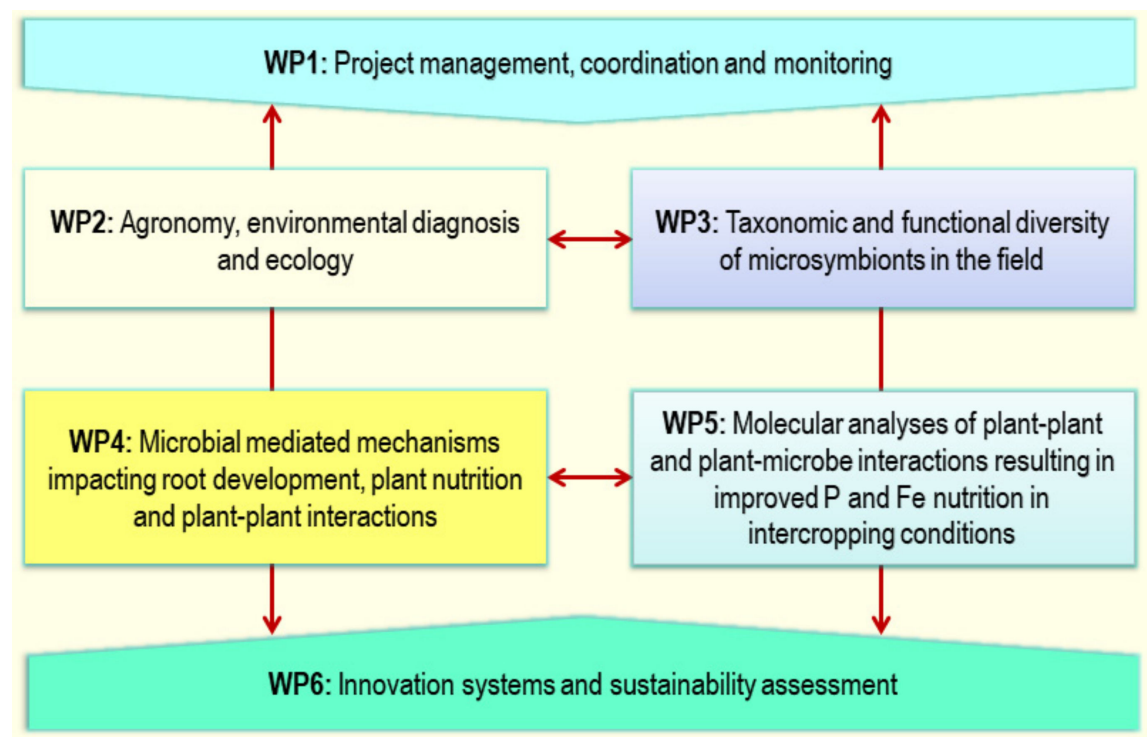

Figure 2. Work packages of CROSYMED project.

WP1 "Project management, coordination, and monitoring" will ensure the scientific, technical, and administrative co-ordination of the whole project. In particular, it will (i) manage the flow of information to guarantee the integration of all the different activities; (ii) organize the exchange of common biological material and measured parameters among the different WPs in order to be able to integrate all the collected results in a data meta-analysis; (iii) promote the mobility of Master's or Ph.D. students and organize two international summer schools; and (iv) promote the international visibility of the program and participating scientists through building links with other networks, soliciting partners to publish and helping the development of training networks.

WP2 "Agronomy, environmental diagnosis, and ecology" will address the overall objective of testing, in the farmer's field conditions of the reference agroecosystem, the agricultural and environmental interest and feasibility of symbioses between legumes and soil microorganisms in a participatory approach with the farmers as final users to carry out tests (simple trials) in a network of field plots including a set of farmer plots identified on the basis of WP6 and the corresponding plots in the field factorial experiments monitored by WP3 in order to link (i) the studies in WP2 with the sustainability evaluation performed in WP6 and (ii) the data, diagnoses, and indicators obtained in WP2 with the mechanisms and processes studied in WP3 and WP4. The diagnoses of the biophysical environment of the network of field plots according to their location on existing regional maps will be performed in coordination with WP1 concerning data management and data integration and WP6 for the selection of the farmers' fields. The field study of the legumes and their symbionts will provide data about the agro-physiological performances of symbioses by measuring the plant growth and yield components, nodulation and symbiotic nitrogen fixation, mycorrhizal infection, and the variability of some biophysical factors such as the pedological conditions. The data of both tasks will be supplied to the meta-analysis of the data to be treated in a common approach with data of WP6 over three successive years with the farmer's local legume as a perennial reference and indicator of the interannual fluctuations. An enhancement of the performance of the symbioses will be sought from the results obtained in WP3: in the first year, the symbiosis will depend on native rhizobia and mycorrhiza, but in the following seasons, strains released in WP3 will be inoculated in fields lacking efficient microorganisms. The soil samples from each reference agroecosystem will be passed to WP2 for analysis of the N and P biogeochemical cycles and to WP3 
for relevant isolation among soil-microorganism diversity. The data will be supplied to the sustainability analysis in WP6 with the initiation of technology transfer for the most field-efficient symbioses.

The overall approach of this WP takes into account the spatial variability of the biophysical characteristics of the agroecosystems, which is conceptualized at the following nested scales: (i) a "global" scale defined by the whole set of plots of all the reference agroecosystems studied in CROSYMED, which includes the climatic gradient between the Mediterranean zones; (ii) the reference agroecosystem scale including the set of plots of each reference agroecosystem, which can include some soil type and landscape variations; (iii) the plot scale with the intraplot variability of the physicochemical conditions in the soils; and (iv) the plant scale including the variability between the rhizospheric zone and the bulk soil outside the rhizosphere. The network of field plots will include, for each reference agroecosystem, approximately 20 farmer plots identified on the basis of the results of WP6.

WP3 "Taxonomic and functional diversity of microsymbionts in the field" aims at investigating the genetic diversity of cereals and legumes in the adaptation to Fe and $\mathrm{P}$ deficiencies in interaction with the functional diversity of rhizobia and mycorrhiza and whether this diversity mitigates the negative effects of soil constraints, focusing on agroecosystems where the intercropping outputs have been the highest. It will (i) assess relationships between the genetic diversity and different enzymatic or transport functions associated with P or Fe nutrition and (ii) provide selected microbial strains to WP2 (for inoculation tests in agroecosystems of farmers from the participating network) and WP4 and WP5 (for ecophysiological and molecular analyses).

WP4 "Microbial mechanisms impacting root development, plant nutrition, and plant-plant interactions" will assess the contribution of mycorrhiza and rhizobia to ecological processes at the community level and to physiological mechanisms at the plant level. WP4.1 will aim at understanding (i) the contribution of P acquisition by mycorrhiza to the efficiency of $\mathrm{N}_{2}$ fixation of six chickpea cultivars and the implication of mycorrhiza in plant-plant interactions and (ii) the microbial mechanisms involved in plant-plant facilitation. First, greenhouse experiments will select a chickpea genotype among those used in WP2 adapted to P-deficient conditions, showing high mycorrhizal colonization rates and efficient symbiotic $\mathrm{N}_{2}$ fixation (using ${ }^{15} \mathrm{~N}$-labelled urea). This chickpea genotype, together with one durum wheat cultivar (tested in WP2), will then be used as a reference couple to assess the efficiency of intercropping compared to monocropping and the underlying mechanisms. Experiments will be performed in pots in low P and N soil (one chickpea and two wheat individuals, inoculation with the reference mycorrhizal isolate used in the initial screening experiment). Either the legume or the cereal will be labeled with ${ }^{15} \mathrm{~N}$ to follow bidirectional $\mathrm{N}$ transfer between plants under three soil partitioning conditions: no separation, allowing root contact between plants; separation by a fine mesh $(25-45 \mu \mathrm{m})$ to separate root systems and allow only fungus-mediated exchanges; and complete separation between plants through trenching. As mycorrhizal fungi harbor a large functional diversity, this experiment will be repeated using a complex indigenous mycorrhizal community (identified in WP2 and WP3), assessing the importance of diversity in the previously identified mechanisms.

WP4.2 will aim at investigating, in wheat and chickpea, the impact of selected microbes (rhizobia + mycorrhiza) on (i) root architecture (experiments carried out using rhizoboxes) and (ii) on root hair development (as described by Poitout et al. [32]). Another objective (not essential to the achievement of this WP) will be to develop software allowing automatic image analysis for root hair elongation phenotyping. WP4.1 and WP4.2 will be performed with a reference wheat-chickpea cultivar couple (from WP2) associated with laboratory microbe strains (year 1) and, thereafter, microbial strains and/or plant cultivars selected from WP2 and WP3, and it will be performed in coordination with WP4.1 and WP4.2.

WP5 "Molecular analyses of plant-plant and plant-microbe interactions resulting in improved $\mathbf{P}$ and Fe nutrition in intercropping conditions" will employ Q-RT-PCR to 
investigate plants grown in greenhouses on artificial substrates and nutrient solutions mimicking high $\mathrm{pH}$ and low nutrient ( $\mathrm{P}$ and $\mathrm{Fe}$ ) availability, assessing the expression levels of genes likely to play a role in (i) P solubilization/nutrition (especially phytases and phosphatases), (ii) Fe nutrition (FRO1 reductase and IRT1 and NRamp transporters for the legume), and (iii) TOM1 siderophore excretion systems and YS1 Fe-chelate transporter for the cereal [18].

Q-RT-PCR and in situ PCR or hybridization analyses will be carried out according to standard protocols currently mastered by members of our consortium [33]. The draft genome sequence of chickpea and the genome sequence information presently available for durum wheat (obtained from our scientific network) will be used for gene identification and primer design. The plant materials, inoculation microbial strains, and growth conditions used will be the same as in WP4.

WP6 "Innovation systems and sustainability assessment" will promote interactions with the farmers and local policy-makers for the development of grain-legume crops, microbial inoculants, and technical practices by characterizing the regional context, the operation of farms, and the current agricultural activities in reference agroecosystems; identifying possible innovation systems for the legume alternatives with the description of past innovation trajectories for the different case studies; performing an evaluation of the sustainability of the cropping system with grain-legume crops for each farmer participating in the project by means of indicators taking into account their economic performance and ecological services; and organizing field visits and restitution meetings with the farmers in parallel to those of the consortium. Four main actions are planned within this WP: (i) characterizing agroecosystems, (ii) identifying potential innovatory systems, (iii) evaluating agroecosystems, and (iv) exchange among actors.

Characterizing agroecosystems: This action will promote interactions with the farmers and local policy-makers for the development of grain-legume crops, microbial inoculants, and technical practices by characterizing the regional context, the operation of farms, and the current agricultural activities in reference agroecosystems.

Identifying potential innovatory systems: In the different case studies, past innovation results will be described to identify possible innovatory systems for the legume alternatives. Different actors will be consulted as to the relevance, possible drawbacks, opportunities, and potential agroecological niches for legume alternatives within local agroecosystems.

Evaluating agroecosystems: For each farmer participating in the project, an evaluation of the sustainability of the agroecosystem will be performed. In this evaluation, indicators of economic performance and ecological benefits will be taken into account for an integrated evaluation at the farm scale.

Exchange among actors: The interaction with and between actors is essential for the evaluation of agroecosystems and the identification of innovatory systems. Interaction between actors will be assured by the organization of collective visits to field trials, targeted feedback meetings, and focus groups.

\subsection{Innovative Approach}

We propose an interdisciplinary approach combining soil microbiology and ecology, agronomy, ecophysiology, plant physiology and molecular biology, and socioeconomic analysis in order to identify the best-performing associations of crop genotypes for low ( $\mathrm{N}$ and $\mathrm{P}$ ) input agriculture. This project is based on a combination of research conducted in controlled conditions (from the scale of mesocosm to field plot in experimental stations) and participatory research (in a network of farmers' plots) (Figure 3). Our central hypothesis is that the performance of a crop plant community in terms of nutrient acquisition and use efficiency can be explained by ecological concepts such as facilitation and niche complementarity. We assume that these processes are enhanced in complex plant communities and at low levels of soil N, P, and Fe resource availability. In order to choose the best-performing associations (in Mediterranean agroecosystems) of species or genotypes, the ambitious objective of the project is to increase our understanding of 
plant-plant and plant-microbe interactions that underlie functional complementarity and facilitation/competition. The ambition is large since the rhizosphere is here considered with a broad view. The recent discovery by our consortium that some rhizobial strains can behave as bona fide PGPB upon interaction with some durum wheat cultivars in a way similar to that we have recently reported in Arabidopsis thaliana [32] actually opens very novel and stimulating perspectives.

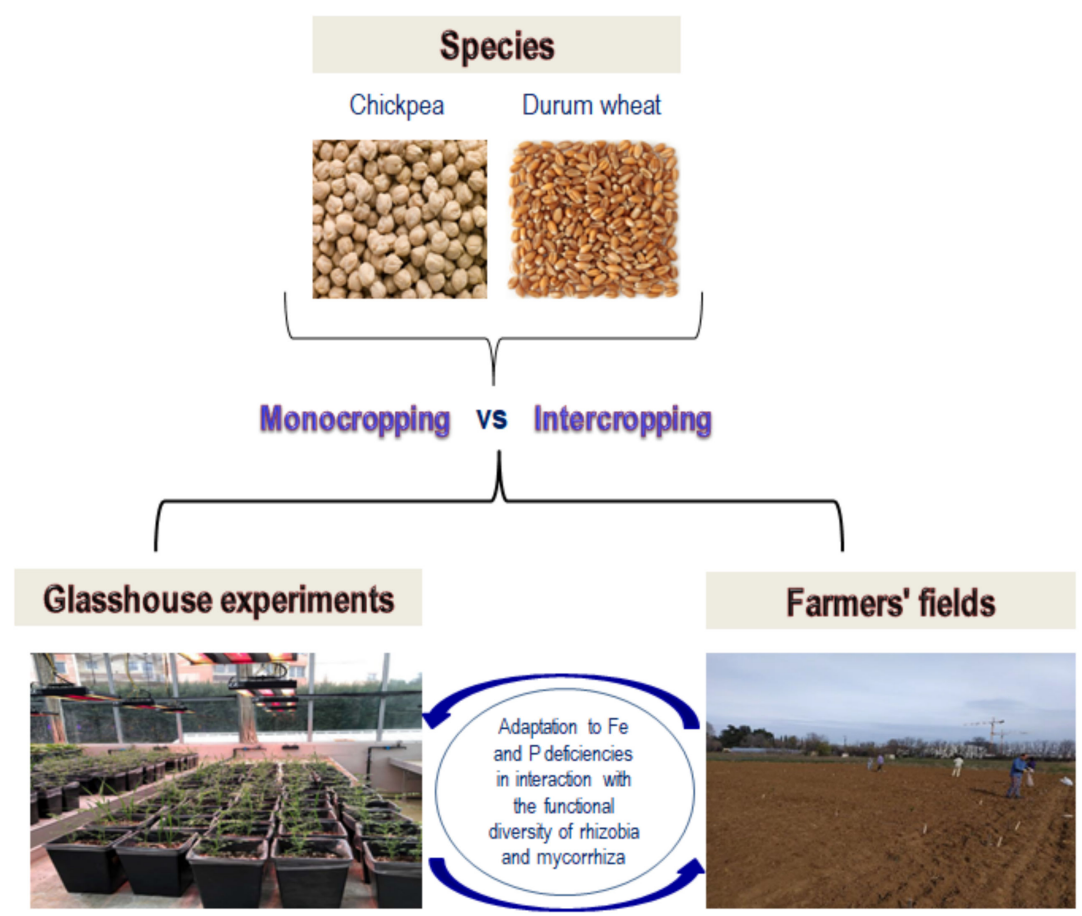

Figure 3. Experimental design for evaluation of cereal association with legumes and their symbionts (rhizobia and mycorrhiza).

\section{Expected Impacts}

This program should contribute to the development of more sustainable agronomical practices relying on the optimization of positive ecological interactions in Mediterranean soils. Using wheat and local varieties of chickpeas in the project should also help in identifying the cultivars most suited for intercropping in Mediterranean agroecosystems. These impacts are particularly relevant since they help save money for the farmers. Indeed, lesser use of fertilizers means lesser expenses in acquiring them. Moreover, legumes are expected to occupy a greater place in the human diet, which should make them more and more profitable in the near future.

Author Contributions: M.L. and H.S. conceived, designed, and wrote the paper and approved the final draft. S.B., E.T., M.F., W.H., and P.R. corrected and approved the final draft. All authors have read and agreed to the published version of the manuscript.

Funding: Enhancing Nutrient Use Efficiency through Legumes in Agroecosystems of the Mediterranean Basin (CROSYMED) is funded through the ARIMNet2 (2017) Joint Call by the following funding agencies: Ministry of Higher Education and Scientific Research represented by the Directorate General for Scientific Research and Technological Development (Algeria); Agence Nationale de la Recherche (France); Ministry of National Education, Vocational Training, Higher Education and Scientific Research represented by the Secretary of State for Higher Education \& Scientific Research (SEESRS) (Morocco); Ministry of Higher Education and Scientific Research (Tunisia); and Hellenic Agricultural Organization "Demeter" (Greece). ARIMNet2 (ERA-NET) has received funding from the European Union's Seventh Framework Programme for research, technological development, and demonstration under grant agreement No. 618127.

Institutional Review Board Statement: Not applicable. 
Informed Consent Statement: Not applicable.

Data Availability Statement: Data sharing not applicable.

Conflicts of Interest: The authors declare no conflict of interest.

\section{References}

1. Vance, C.P.; Uhde-Stone, C.; Allan, D.L. Phosphorus acquisition and use: Critical adaptations by plants for securing a nonrenewable resource. New Phytol. 2003, 157, 423-447. [CrossRef]

2. Tilman, D.; Cassman, K.G.; Matson, P.A.; Naylor, R.; Polasky, S. Agricultural sustainability and intensive production practices. Nature 2002, 418, 671-677. [CrossRef] [PubMed]

3. Mackenzie, F.T.; Ver, L.M.; Lerman, A. Century-scale nitrogen and phosphorus controls of the carbon cycle. Chem. Geol. 2002, 190, 13-32. [CrossRef]

4. Tilman, D. Global environmental impacts of agricultural expansion: The need for sustainable and efficient practices. Proc. Natl. Acad. Sci. USA 1999, 96, 5995-6000. [CrossRef] [PubMed]

5. Bedoussac, L.; Journet, E.P.; Hauggaard-Nielsen, H.; Naudin, C.; Corre-Hellou, G.; Jensen, E.S.; Prieur, L.; Justes, E. Ecological principles underlying the increase of productivity achieved by cereal-grain legume intercrops in organic farming. A review. Agron. Sustain. Dev. 2015, 35, 911-935. [CrossRef]

6. Latati, M.; Bargaz, A.; Belarbi, B.; Lazali, M.; Benlahrech, S.; Tellah, S.; Kaci, G.; Drevon, J.J.; Ounane, S.M. The intercropping common bean with maize improves the rhizobial efficiency, resource use and grain yield under low phosphorus availability. Eur. J. Agron. 2016, 72, 80-90. [CrossRef]

7. Madembo, C.; Mhlanga, B.; Thierfelder, C. Productivity or stability? Exploring maize-legume intercropping strategies for smallholder Conservation Agriculture farmers in Zimbabwe. Agric. Syst. 2020, 185, 1-14. [CrossRef]

8. Li, L.; Tilman, D.; Lambers, H.; Zhang, F.S. Plant diversity and over yielding: Insights from belowground facilitation of intercropping in agriculture. New Phytol. 2014, 203, 63-69. [CrossRef] [PubMed]

9. Zhang, D.; Sun, Z.; Feng, L.; Bai, W.; Yang, N.; Zhang, Z.; Guijuan, D.; Chen, F.; Qian, C.; Qi, W.; et al. Maize plant density affects yield, growth and source-sink relationship of crops in maize/peanut intercropping. Field Crop. Res. 2020, 257, 1-10. [CrossRef]

10. Connoly, J.; Goma, H.C.; Rabhim, K. The information content of indicators in intercropping research. Agr. Ecosyst. Environ. 2001, 97, 191-207. [CrossRef]

11. Li, L.; Li, S.M.; Sun, J.H.; Zhou, L.L.; Bao, X.G.; Zhang, H.G.; Zhang, F.S. Diversity enhances agricultural productivity via rhizosphere phosphorus facilitation on phosphorus-deficient soils. Proc. Natl. Acad. Sci. USA 2007, 104, 11192-11196. [CrossRef]

12. Jensen, E.S.; Bedoussac, L.; Carlsson, C.; Journet, E.P.; Justes, E.; Hauggaard-Nielsen, H. Enhancing yields in organic crop production by eco-functional intensification. Sustain. Agric. Res. 2015, 4, 42-50. [CrossRef]

13. Zhang, C.; Dong, Y.; Tang, L.; Zheng, Y.; Makowski, D.; Yu, Y.; Zhang, F.; van der Werf, W. Intercropping cereals with faba bean reduces plant disease incidence regardless of fertilizer input; A meta-analysis. Eur. J. Plant Pathol. 2019, 154, 931-942. [CrossRef]

14. Hauggaard-Nielsen, H.; Jensen, E.S. Facilitative root interactions in intercrops. Plant Soil 2005, 274, 237-250. [CrossRef]

15. Jensen, E.S.; Carlsson, G.; Hauggaard-Nielsen, H. Intercropping of grain legumes and cereals improves the use of soil N resources and reduces the requirement for synthetic fertilizer N: A global-scale analysis. Agron. Sustain. Dev. 2020, 40, 5. [CrossRef]

16. Zhang, F.; Li, L. Using competitive and facilitative interactions in intercropping systems enhances crop productivity and nutrient-use efficiency. Plant Soil 2003, 248, 305-312. [CrossRef]

17. Zhang, F.; Shen, J.; Li, L.; Liu, X. An overview of rhizosphere processes related with plant nutrition in major cropping systems in China. Plant Soil 2004, 260, 89-99. [CrossRef]

18. Xue, Y.; Xia, H.; Christie, P.; Zhang, Z.; Li, L.; Tang, C. Crop acquisition of phosphorus, iron and zinc from soil in cereal/legume intercropping systems: A critical review. Ann. Bot. 2016, 117, 363-377. [CrossRef]

19. Tang, X.; Zhang, C.; Yu, Y.; Shen, J.; van der Werf, W.; Zhang, F. Intercropping legumes and cereals increases phosphorus use efficiency; A meta-analysis. Plant Soil 2020, 1-16.

20. Cu, S.T.T.; Hutson, J.; Schuller, K.A. Mixed culture of wheat (Triticum aestivum L.) with white lupin (Lupinus albus L.) improves the growth and phosphorus nutrition of the wheat. Plant Soil 2005, 272, 143-151. [CrossRef]

21. Lazali, M.; Bargaz, A. Examples of belowground mechanisms enabling legumes to mitigate phosphorus deficiency. In Legume Nitrogen Fixation in Soils with Low Phosphorus Availability; Sulieman, S., Tran, L.S.P., Eds.; Springer International Publishing: Cham, Switzerland, 2017; pp. 135-152.

22. Hinsinger, P.; Plassard, C.; Tang, C.; Jaillard, B. Origins of root-induced $\mathrm{pH}$ changes in the rhizosphere and their responses to environmental constraints: A review. Plant Soil 2003, 248, 43-59. [CrossRef]

23. Betencourt, E.; Duputel, M.; Colomb, B.; Desclaux, D.; Hinsinger, P. Intercropping promotes the ability of durum wheat and chickpea to increase rhizosphere phosphorus availability in a low P soil. Soil Biol. Biochem. 2012, 46, 181-190. [CrossRef]

24. Li, S.M.; Li, L.; Zhang, F.S.; Tang, C. Acid phosphatase role in chickpea/maize intercropping. Ann. Bot. 2004, 94, 297-303. [CrossRef]

25. Gunes, A.; Bagci, E.G.; Inal, A. Interspecific facilitative root interactions and rhizosphere effects on phosphorus and iron nutrition between mixed grown chickpea and barley. J. Plant Nutr. 2007, 30, 1455-1469. [CrossRef] 
26. Lazali, M.; Drevon, J.J. Role of acid phosphatase in the tolerance of the rhizobial symbiosis with legumes to phosphorus deficiency. Symbiosis 2018, 76, 221-228. [CrossRef]

27. Rengel, Z.; Marschner, P. Nutrient availability and management in the rhizosphere: Exploiting genotypic differences. New Phytol. 2005, 168, 305-312. [CrossRef] [PubMed]

28. Wissuwa, M.; Mazzola, M.; Picard, C. Novel approaches in plant breeding for rhizosphere-related traits. Plant Soil 2009, 321, 409-430. [CrossRef]

29. Duchene, O.; Vian, J.F.; Celette, F. Intercropping with legume for agroecological cropping systems: Complementarity and facilitation processes and the importance of soil microorganisms. A review. Agric. Ecosyst. Environ. 2017, 240, 148-161. [CrossRef]

30. Cassman, K.G. Ecological intensification of cereal production systems: Yield potential, soil quality, and precision agriculture. Proc. Natl. Acad. Sci. USA 1999, 96, 5952-5959. [CrossRef]

31. Irshad, U.; Brauman, A.; Villenave, C.; Plassard, C. Phosphorus acquisition from phytate depends on efficient bacterial grazing, irrespective of the mycorrhizal status of Pinus pinaster. Plant Soil 2012, 358, 155-168. [CrossRef]

32. Poitout, A.; Martinière, A.; Kucharczyk, B.; Queruel, N.; Silva-Andia, J.; Mashkoor, S.; Gamet, L.; Varoquaux, F.; Paris, N.; Sentenac, H.; et al. Local signalling pathways regulate the Arabidopsis root developmental response to Mesorhizobium loti inoculation. J. Exp. Bot. 2017, 68, 1199-1211. [CrossRef] [PubMed]

33. Tounsi, S.; Ben Amar, S.; Masmoudi, K.; Sentenac, H.; Brini, F.; Véry, A.A. Characterization of two HKT1; 4 transporters from Triticum monococcum to elucidate the determinants of the wheat salt tolerance Nax1 QTL. Plant Cell Physiol. 2016, 57, $2047-2057$. [CrossRef] [PubMed] 